\title{
Variation of Elements in Shirala Tahsil of Black Soil by Using Spent Wash
}

\author{
Dr. A. B. Patil \\ Assistant Professor, D. A. B. N. Naik College, Chikhali, Tal-Shirala. Dist-Sangli, India
}

\begin{abstract}
In this paper the different soil samples are analyzed [1]. Acidity is measured on pH scale, so as change of hydrogen ion activity is observed Fine particles of quartz, feldspar, mica, carbonates of metals, oxide \& sulphides of iron are present in soil along with organic matter and micro nutrients[2-3]. Zn, Mn, Fe, Cu, are chemically analyzed from the soil are maintained. to balance between the natural constituents of soil is lost,by using the spent wash these constituents have balanced and crop to made healthy and to reduce the fertilizers [4].
\end{abstract}

Keywords: Elemental analysis, Black soil

\section{Introduction}

An accurate soil analysis is necessary to understanding the fertility of soil, we use Soil sampling and testing provides an excellent inventory of plant available nutrients and other soil factors important for crop production [5]. The purpose of soil analysis is to assess the deficiency of available nutrients for crop growth. Soil properties are determined by both field and laboratory test method [6-7]. The chemistry of a soil determines its ability to supply available plant nutrients and affects its physical properties and the health of its microbial pollination. Soil is the very base of agriculture. Due to this reason to understand the nature of soil \& their capacity to produce healthy plant [8].

\section{Methods of Analysis}

1) Collection of the Sample: Sample is collected as per the recommended procedure.

2) Required Chemicals:

All of the chemicals are prepared as per the recommended procedure. All of the chemicals are used AR grade.

3) Instruments

a) $\mathrm{PH}$ meters- Model EQ-610

b) Conductivity Meter- Model EG-660

c) Atomic Absorption Spectrophotometer-Mode

d) Spectrophotometer

\section{Result of analysis: [9-10]}

Table 1: Result of analysis of Soil before addition of spent

\begin{tabular}{|c|c|c|c|c|}
\hline Sr.No & Parameter & Unit & Observed value & Limit \\
\hline 1 & $\mathrm{pH}$ & & 6.15 & $6.5-8.5$ \\
\hline 2 & E-Conductivity & Mmhos/cm & 0.37 & $<4.0$ \\
\hline 3 & Nitrogen & Kg/ha & 191.00 & $100-200$ \\
\hline 4 & Phosphorous & $\mathrm{Kg} / \mathrm{ha}$ & 16.00 & $30-40$ \\
\hline 5 & Potassium & $\mathrm{Kg} / \mathrm{h}$ & 512.00 & $110-280$ \\
\hline 6 & Organic Carbon & $\%$ & 0.87 & $>0.50$ \\
\hline 7 & Calcium & $\%$ & 5.10 & $0.1-3.2$ \\
\hline 8 & Copper ( $\mathrm{Cu})$ & Ppm & 0.66 & $0.3-0.5$ \\
\hline 9 & Iron $(\mathrm{Fe})$ & ppm & 4.90 & $2.5-4.5$ \\
\hline 10 & Manganese (Mn) & ppm & 0.72 & $1.0-2.0$ \\
\hline 11 & Zinc (Zn ) & ppm & 0.15 & $0.5-1.2$ \\
\hline
\end{tabular}

Table 2

\begin{tabular}{|c|c|c|c|c|}
\hline Sr. No & Parameter & Unit & Observed value & Limit \\
\hline 1 & $\mathrm{pH}$ & & 6.96 & $6.5-8.5$ \\
\hline 2 & E-Conductivity & Mmhos/cm & 0.53 & $<4.0$ \\
\hline 3 & Nitrogen & $\mathrm{Kg} / \mathrm{ha}$ & 140.00 & $100-200$ \\
\hline 4 & Phosphorous & $\mathrm{Kg} / \mathrm{ha}$ & 51.00 & $30-40$ \\
\hline 5 & Potassium & $\mathrm{Kg} / \mathrm{h}$ & 354.00 & $110-280$ \\
\hline 6 & Organic Carbon & $\%$ & 0.64 & $>0.50$ \\
\hline 7 & Calcium & $\%$ & 2.25 & $0.1-3.2$ \\
\hline 8 & Copper ( Cu) & $\mathrm{Ppm}$ & 0.53 & $0.3-0.5$ \\
\hline 9 & Iron (Fe) & $\mathrm{ppm}$ & 4.00 & $2.5-4.5$ \\
\hline 10 & Manganese (Mn) & $\mathrm{ppm}$ & 0.42 & $1.0-2.0$ \\
\hline 11 & Zinc (Zn ) & $\mathrm{ppm}$ & 0.70 & $0.5-1.2$ \\
\hline
\end{tabular}

Table 3: Result of analysis of Soil after addition of spent wash

\begin{tabular}{|c|c|c|c|c|}
\hline Sr. No & Parameter & Unit & Observed value & Limit \\
\hline 1 & $\mathrm{pH}$ & & 7.05 & $6.5-8.5$ \\
\hline 2 & E-Conductivity & Mmhos/cm & 2.58 & $<4.0$ \\
\hline 3 & Nitrogen & $\mathrm{Kg} / \mathrm{ha}$ & 409.00 & $100-200$ \\
\hline 4 & Phosphorous & $\mathrm{Kg} / \mathrm{ha}$ & 85.00 & $30-40$ \\
\hline 5 & Potassium & $\mathrm{Kg} / \mathrm{h}$ & 3897.00 & $110-280$ \\
\hline 6 & Organic Carbon & $\%$ & 1.86 & $>0.50$ \\
\hline 7 & Calcium & $\%$ & 2.75 & $0.1-3.2$ \\
\hline 8 & Copper ( Cu) & $\mathrm{Ppm}$ & 2.00 & $0.3-0.5$ \\
\hline 9 & Iron $(\mathrm{Fe})$ & $\mathrm{ppm}$ & 7.55 & $2.5-4.5$ \\
\hline 10 & Manganese $(\mathrm{Mn})$ & $\mathrm{ppm}$ & 20.00 & $1.0-2.0$ \\
\hline 11 & Zinc $(\mathrm{Zn})$ & $\mathrm{ppm}$ & 1.87 & $0.5-1.2$ \\
\hline
\end{tabular}

Table 4

\begin{tabular}{|c|c|c|c|c|}
\hline Sr.No & Parameter & Unit & Observed value & Limit \\
\hline 1 & $\mathrm{pH}$ & & 7.35 & $6.5-8.5$ \\
\hline 2 & E-Conductivity & Mmhos/cm & 2.98 & $<4.0$ \\
\hline 3 & Nitrogen & $\mathrm{Kg} / \mathrm{ha}$ & 910.00 & $100-200$ \\
\hline 4 & Phosphorous & $\mathrm{Kg} / \mathrm{ha}$ & 42.00 & $30-40$ \\
\hline 5 & Potassium & $\mathrm{Kg} / \mathrm{h}$ & 3265.00 & $110-280$ \\
\hline 6 & Organic Carbon & $\%$ & 4.14 & $>0.50$ \\
\hline 7 & Calcium & $\%$ & 3.75 & $0.1-3.2$ \\
\hline 8 & Copper $(\mathrm{Cu})$ & $\mathrm{Ppm}$ & 4.10 & $0.3-0.5$ \\
\hline 9 & Iron $(\mathrm{Fe})$ & $\mathrm{ppm}$ & 17.70 & $2.5-4.5$ \\
\hline 10 & Manganese $(\mathrm{Mn})$ & $\mathrm{ppm}$ & 21.00 & $1.0-2.0$ \\
\hline 11 & Zinc $(\mathrm{Zn})$ & $\mathrm{ppm}$ & 4.00 & $0.5-1.2$ \\
\hline
\end{tabular}

\section{Conclusion}

Initially all parameters of soil sample are analyzed .These 


\section{International Journal of Science and Research (IJSR) \\ ISSN (Online): 2319-7064 \\ Index Copernicus Value (2013): 6.14 | Impact Factor (2015): 6.391}

observed parameters and its value are $\mathrm{pH}, \mathrm{E}$ - conductivity, nitrogen, .phosphorous, potassium, 6.15, 0.37, 191.00, $16.00,512.00 \mathrm{~kg} / \mathrm{ha}$ and calcium\& organic carbon.5.10, $0.87 \%$ as well as microelements are saw iron, manganese, zinc, copper its value 4.90,0.71,0.15,0.66.ppm (table no.1)

All parameters of soil in second sample are analyzed .These observed parameters and its value are $\mathrm{pH}$, E- conductivity, nitrogen, .phosphorous, potassium, 6.96, 0.53, 140.00, $51.00,354.00 \mathrm{~kg} / \mathrm{ha}$ and calcium\& organic carbon.2.25, $0.64 \%$ as well as microelements are saw iron, manganese, zinc, copper its value 4.00, 0.042, 0.70, 0.53 ppm (table no.2)

Then spent wash was sprayed on the selected plot and then sample collected and analyzed values are $\mathrm{pH}$, Econductivity, nitrogen, phosphorous, potassium, 7.05, 2.58, 409.00, 85.00, 3897.00, kg/ha and calcium, organic carbon $2.75 ; 1.86$; \% as well as microelements are analyzed iron, manganese, zinc, copper the value was found 7.55, 20.00, 1.87, 2.00, ppm. (Table no.3) In the selected second plot sample collected and analyzed values are $\mathrm{pH}, \mathrm{E}-$ conductivity, nitrogen, phosphorous, potassium, 7.35, 2.98, 910.00, 42.00, 3265.00, kg/ha and calcium, organic carbon $3.75 ; 4.14$; \% as well as microelements are analyzed iron, manganese, zinc, copper the value was found 17.70, 21.00, 4.00, 4.10, ppm table no. 4

As per the above conclusion is made up of abruptly increases elements as well as micro elements initial analyzed value mentioned in table no 1,2 and after giving the spent wash value mentioned in table no 3,4 . The better effect observed on the land, it helps to improvement of fertility soil

\section{Acknowledgements}

I take this golden opportunity to express my heartily thanks and deep sense of gratitude U.G.C, Dr.S.M.Patil, Shri.G.S. Khansole, Shri. Patil S. K. Shri. Borage V. I. Who has been a constant source of encouragement to complete this paper work and giving her excellent guidance and suggestion from time to time during course of this work. Lastly, I would like to especially thank to Principal Dr. S. R. Patil for his valuable guidance.

\section{References}

[1] Hall, D.G.M., Reeve, M.J., Thomasson, A.J. and Wright, V.F.(1977). Water retention, porosity, and density of field soils. Soil Survey Technical Monograph No.9, pp77. Harpenden, UK.

[2] Hallett, S.H. \& Bullock, P. \& Baillie, I. (2006) "Towards a World Soil Survey Archive and Catalogue", Soil Use And Management. 3

[3] Van Genuchten, M.Th. (1980). A closed form equation for predicting the hydraulic conductivity of unsaturated soils. Soil Science Society of America Journal 44, 892898.

[4] Hollis, J.M. (2000). A spatial environmental information system for modelling the impact of chemicals. In: Proceedings of the International Congress 'Soil Vulnerability and Sensitivity', Florence, 18-21
October, 1999. Bollettino Della Società Italiana della Scienza del Suolo, 49, 69-88

[5] Avery, B.W. and Bascomb, C.L. (1982). Soil Survey Laboratory Methods. Soil Survey Technical Monograph No.6, pp83. Harpenden, UK.

[6] Bellamy, P.H. and Kibblewhite, M.G. (2004) Performance criteria for soil monitoring. Proceeding of Eurosoil conference, Freiburg, September 2004. p.200201.

[7] Clayden, B and Hollis, J.M. (1984). Critieria for Differentiating Soil Series. Soil Survey Technical Monograph No.17, pp159. Harpenden, UK.

[8] Environment Agency (2004b). Soil, The Hidden Resource. Environment Agency, Bristol.

[9] Mallarino, A.P., and D.J. Wittry. 2004. Efficacy of grid and zone soil sampling approaches for site-specific assessment of phosphorus, potassium $\mathrm{pH}$, and organic matter. Precision Agriculture 5:131-144.

[10] Clay, D.E., J.L. Kleinjan, W.A. Tjentland N. Kitchen, and C.G. Carlson. 2002. Collecting representative soil samples for $\mathrm{N}$ and $\mathrm{P}$ fertilizer recommendations [electronic resource]. Crop Management 